\title{
Tingling in tongue due to alprazolam and paroxetine-induced hypergabaergic activity
}

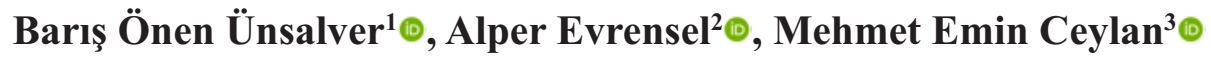 \\ ${ }^{1}$ Department of Medical Documentation and Secreriat, Üsküdar University, Vocational School of Health Services, Istanbul, Turkey \\ ${ }^{2}$ Department of Psychology, Üsküdar University, Istanbul, Turkey \\ ${ }^{3}$ Department of Psychology and Philosophy, Üsküdar University, Istanbul, Turkey
}

DOI: $10.18621 /$ eurj.402017

\begin{abstract}
Paroxetine is a commonly used serotonin-reuptake inhibitor for the treatment of various psychiatric disorders. Available literature is sparse with cases of paresthesia that occur during withdrawal of paroxetine, there are fewer reports of paresthesia during the initiation. Here we report a case of panic disorder who experienced tingling of the tongue during the initiation phase of paroxetine, and whose paresthesia resolved only after the withdrawal of the drug. When paroxetine was introduced, the patient was already on alprazolam monotherapy. Therefore, the previously activated GABAergic state with alprazolam was probably further augmented with paroxetine. We suggest that the serotonin receptor supersensitivity related to panic disorder might have been a vulnerability factor for paresthesia, and the hypergabaergic state caused by alprazolam and paroxetine combination made the paresthesia evident in our case. This is the first report of a case with paresthesia in a combination of alprazolam and paroxetine. We might suggest that in patients who develop paresthesia during psychotropic use, the clinician's first step might be to just decrease the dosage of the drugs before further clinical and laboratory evaluation of the patient for paresthesia.
\end{abstract}

Keywords: paresthesia, paroxetine, alprazolam, hypergabaergic state

Received: March 5, 2018; Accepted: June 22, 2018; Published Online: June 24, 2018

P aroxetine is a commonly used serotonin-reuptake inhibitor (SSRI) for the treatment of various psychiatric disorders. Besides the side-effects common to all SSRIs during the initiation phase, paroxetine is also well-known for discomforting initiation and discontinuation symptoms [1], one of which is paresthesia [2-4]. Paroxetine has been reported to increase the risk difference for paresthesia in $1.7 \%$ of users [1]. While available literature is sparse with cases of paresthesia that occur during withdrawal of paroxetine, there are fewer reports of paresthesia during the initiation $[5,6]$.
Here we report a case who experienced tingling of the tongue during the initiation phase of paroxetine, and whose paresthesia resolved only after the withdrawal of the drug. Written informed consent was taken from the patient prior to reporting.

\section{CASE PRESENTATION}

A 47-year-old female patient with a diagnosis of panic disorder was followed-up by the first author. She had been medication free for two years because she

* Address for correspondence: Barlş Önen Ünsalver, MD., Assistant Professor, Üsküdar University, Vocational School of Health Services, Department of Medical Documentation and Secreriat, NPFeneryolu Tip Merkezi, Ahmet Mithat Efendi Cd. No:17, 34726 Istanbul, Turkey

E-mail: onenunsalver@gmail.com 
had benefited from cognitive therapy and was able to deal with her daily worries. However, after the sudden death of a close relative her anxiety levels increased, insomnia and appetite loss developed and continuous palpitations, and shortness of breath started. After working through her loss and supporting her with alprazolam $0.5 \mathrm{mg}$ twice daily her symptoms continued by the end of one month, and she began experiencing panic attacks. Therefore, paroxetine $10 \mathrm{mg} /$ day was added to the treatment. She had used and benefited from paroxetine $30 \mathrm{mg}$ /day previously without any initiation or discontinuation symptoms, however, this time when the dosage was increased to $30 \mathrm{mg} /$ day by the third week she started complaining about tingling sensations in her tongue. A full blood count and blood biochemistry including vitamin B12, folic acid, magnesium, calcium, iron, vitamin D3, thyroid function tests, liver function tests were all in the normal range. The patient was examined by a neurologist. Cranial imaging was not necessary because the patient was functioning well generally and her neurological symptoms included only the tingling in the tongue.

She had thought this tingling might be related to anxiety and increased alprazolam to $1.5 \mathrm{mg}$ /day daily without any benefit. Therefore we suspected that paroxetine might be causing the tingling, and it was decreased to $20 \mathrm{mg} / \mathrm{day}$, but the tingling sensation stopped only after paroxetine was discontinued altogether. She was started on escitalopram. However, after six weeks of escitalopram $20 \mathrm{mg}$ /day she wanted to give paroxetine another try because her anxiety was still very discomforting and she admitted that her anxiety would seem to get better only after she took alprazolam. Unfortunately, she reported the same tingling sensation on her tongue again after switching to paroxetine. Tingling disappeared after stopping paroxetine. She was started on duloxetine $30 \mathrm{mg} /$ day which was increased up to $60 \mathrm{mg} /$ day. She has not reported any tingling sensations in her tongue and is anxiety free for the past eight months. Naranjo's adverse effect scale was applied retrospectively [7]. The score was 8 .

\section{DISCUSSION}

As a general rule, for the treatment of psychiatric disorders, it is convenient to choose the molecule that the patient had benefited from during previous episodes, that is why paroxetine was selected for our patient. Reappearance and disappearance of the tingling sensation when paroxetine is used and stopped suggests that this paresthesia was caused by paroxetine. Naranjo's adverse effect scale was applied retrospectively. The score was 8. A score of 5-8 for the scale indicates "probable" relation between the drug and the adverse event [7]. Therefore, we can't say that the relation between tingling in the tongue and paroxetine and alprazolam use is not definite but probable. It is of note that she had not previously experienced any important side-effects related to paroxetine before.

Some of the factors that may contribute to adverse drug reactions are age, gender, maternity status, smoking, alcohol use, polypharmacy, drug dosing and drug frequency or the pathophysiology of the disease [8]. Paroxetine is a potent inhibitor of CYP2D6, and this may be responsible for some side-effects related to its use in combination with other drugs. Paroxetine was combined with alprazolam in our patient which is a conventional approach, especially in panic disorder patients to accelerate treatment response at the initiation of SSRI treatment [9]. Alprazolam is neither a substrate nor an inducer of the CYP2D6 system. Therefore alprazolam is not supposed to interact with the metabolism of paroxetine. In a previous study, the combination of paroxetine with alprazolam at steady state in healthy volunteers, there were no pharmacological interactions [10]. Our patient was not on any other drug than alprazolam, was not using alcohol and was not a smoker.

Serotonin receptor supersensitivity has been suggested for the pathophysiology of paresthesia experienced during withdrawal from SSRIs [4]. It has also been reported that patients with panic disorder show serotonin receptor supersensitivity [11]. Therefore, the patient's clinical syndrome of panic disorder itself might have increased her vulnerability to the drug-related paresthesia.

Due to anticholinergic and other receptor features, paroxetine can cause jitteriness or activation syndrome. However, the drug was titrated slowly, starting with $10 \mathrm{mg}$ the first week and reaching 30 $\mathrm{mg}$ /day by the third week. Therefore, probable activation syndrome through $5 \mathrm{HT} 2 \mathrm{C}$ receptor was not 
considered [12]. The patient had no other neurological signs other than the tingling in the tongue. She did not describe increased irritability or any myoclonic activity that would suggest jitteriness.

Benzodiazepine withdrawal may cause paresthesia, but alprazolam dosage remained the same when paroxetine was introduced [13]. When benzodiazepines bind to the GABA A receptor, the receptor is allosterically modulated, and GABA exerts a greater effect on the chloride channel, resulting in stronger inhibition. Benzodiazepines activate GABA receptors [14]. SSRIs increase cortical GABAergic activity [15].

When paroxetine was introduced, she was already on alprazolam monotherapy. Therefore, the previously activated GABAergic state was probably further augmented with paroxetine.

It might be argued that serotonin receptor supersensitivity related to panic disorder might be a vulnerability factor for paresthesia, and the hypergabaergic state caused by alprazolam and paroxetine combination made the paresthesia evident.

\section{CONCLUSION}

This is the first report of a case with paresthesia in a combination of alprazolam and paroxetine. We might suggest that in patients who develop paresthesia during psychotropic use, the clinician's first step might be to just decrease the dosage of the drugs before further clinical and laboratory evaluation of the patient for paresthesia.

\section{Informed consent}

Written informed consent was obtained from the patient for publication of this case report and any accompanying images.

\section{Conflict of interest}

The authors declared that there are no potential conflicts of interest with respect to the research, authorship, and/or publication of this article.

\section{REFERENCES}

[1] Aursnes I, Gjertsen MK. Common adverse events associated with an SSRI: meta-analysis of early paroxetine data. Pharmacoepidemiol Drug Saf 2008:17:707-13.

[2] Black K, Shea C, Dursun S, Kutcher S. Selective serotonin reuptake inhibitor discontinuation syndrome: proposed diagnostic criteria. J Psychiatry Neurosci 2000:25:255-61.

[3] Price JS, Waller PC, Wood SM, MacKay AV. A comparison of the post-marketing safety of four selective serotonin re-uptake inhibitors including the investigation of symptoms occurring on withdrawal. $\mathrm{Br} \mathrm{J}$ Clin Pharmacol 1996;42:757-63.

[4] Coupland NJ, Bell CJ, Potokar JP. Serotonin reuptake inhibitor withdrawal. J Clin Psychopharmacol 1996:16:356-62.

[5] Berigan TR, Cannard AW, Cannard KR. Transient, paroxysmal, shock-like paresthesias associated with paroxetine initiation. J Clin Psychiatry 1997;58:175-6.

[6] Duggal HS. Paroxetine-induced limb anesthesia. Gen Hosp Psychiatry 2003:25:51-2.

[7] Naranjo CA, Busto U, Sellers EM, Sandor P, Ruiz I, Roberts EA, et al. A method for estimating the probability of adverse drug reactions. Clin Pharmacol Ther 1981:30:239-45.

[8] Alomar MJ. Factors affecting the development of adverse drug reactions. Saudi Pharm J 2014:22:83-94.

[9] Katzelnick DJ, Saidi J, Vanelli MR, Jefferson JW, Harper JM, McCrary KE. Time to response in panic disorder in a naturalistic setting: combination therapy with alprazolam orally disintegrating tablets and serotonin reuptake inhibitors compared to serotonin reuptake inhibitors alone. Psychiatry (Edgmont) 2006:3:39-49.

[10] Calvo G, García-Gea C, Luque A, Morte A, Dal-RéR, Barbanoj M. Lack of pharmacologic interaction between paroxetine and alprazolam at steady state in healthy volunteers. J Clin Psychopharmacol 2004:24:268-76.

[11] Kahn RS, Asnis GM, Wetzler S, van Praag HM. Neuroendocrine evidence for serotonin receptor hypersensitivity in panic disorder. Psychopharmacology (Berl) 1988:96:360-4.

[12] Harada T, Sakamoto K, Ishigooka J. Incidence and predictors of activation syndrome induced by antidepressants. Depress Anxiety 2008:25:1014-9.

[13] Smith DE, Wesson DR, Sabnani SA. Benzodiazepine and other sedative-hypnotic dependence. In: Gabbard GO, ed., Gabbard's Treatments of Psychiatric Disorders, 4th ed. Arlington VA:American Psychiatric Publishing; 2007, p.209.

[14] Raj A, Sheehan D. Benzodiazepines. In: Schatzberg AF, Nemeroff CB, eds., The American Psychiatric Publishing Textbook of Psychopharmacology, 3rd ed. Arlington VA:American Psychiatric Publishing; 2003, pp.274-375.

[15] Bhagwagar Z, Wylezinska M, Taylor M, Jezzard P, Matthews PM, Cowen PJ. Increased brain GABA concentrations following acute administration of a selective serotonin reuptake inhibitor. Am J Psychiatry 2004:161:368-70. 